\title{
Gastroesophageal Reflux in Children: Is There a Place for the Upper Gastrointestinal Study?
}

\author{
Caroline E. Blane, Michael D. Klein, Robert A. Drongowski, Teresa M. Sarahan, \\ John R. Wesley, and Arnold G. Coran \\ Departments of Surgery (Section of Pediatric Surgery) and Radiology (Section of Pediatric Radiology), \\ The University of Michigan Medical Center, Ann Arbor, Michigan, USA
}

\begin{abstract}
Objective tests for gastroesophageal reflux in children have shown only fair correlation with clinical symptoms. Thirty-four children referred to the pediatric surgery service for evaluation of gastroesophageal reflux had both 24-hour $\mathrm{pH}$ probe monitoring and standardized upper gastrointestinal examinations. A total of 16 children $(47 \%)$ had documented significant or pathologic gastroesophageal reflux, 11 on $\mathrm{pH}$ monitors and 9 on contrast examinations. There were 4 in whom both tests were positive. None of the $\mathrm{pH}$ monitoring criteria correlated with the radiographic studies. The patient population documented by contrast study did not differ from the general testpositive population by age or associated clinical findings. The 2 studies probably measure different aspects of significant gastroesophageal reflux, are confirmatory and complementary, and must be correlated with the clinical symptoms.
\end{abstract}

Key words: Gastroesophageal reflux, radiography - Esophagus, pH monitoring.

The incidence of gastroesophageal reflux in children has been estimated to be 1:500 infants [1]. In the absence of any therapy, the combined mortality and morbidity is approximately $10 \%$ [1]. In the pediatric age group many associated conditions are seen with gastroesophageal reflux including esophageal atresia, gastroschisis, omphalocele, sudden infant death syndrome, and brain damage [2-4]. With continually improving medical and surgical therapy for many of these conditions and

Address reprint requests to: Caroline E. Blane, M.D., Department of Radiology, Section of Pediatric Radiology, C.S. Mott Children's Hospital, University of Michigan Hospitals, Ann Arbor, MI 48109-0010, USA more awareness of the problems associated with gastroesophageal reflux, we are seeing a greater number of children with a variety of respiratory and feeding complaints thought to be due to gastroesophageal reflux.

Although the upper gastrointestinal study is universally available, there has been a recent proliferation of tests for the diagnosis of gastroesophageal reflux $[1,5,6]$. One of these, esophageal $\mathrm{pH}$ monitoring, has gained popularity $[5,7,8,9]$. The reported objectivity, reliability, and sensitivity of 24-hour esophageal $\mathrm{pH}$ monitoring in children [5] have led to the question of whether there is any place for contrast studies in children.

\section{Materials and Methods}

All children referred to the pediatric surgery service for evaluation of gastroesophageal reflux for the period of 1 year were included in this study. There were 16 boys and 18 girls who ranged in age from 3 months to 16 years (mean, 2.6 years). There were 18 patients under the age of 2 years and 16 patients older than 2 years. Twelve of the 34 patients $(35 \%)$ had brain damage and 2 other children had multiple problems including congenital heart disease. All children underwent both an upper gastrointestinal study and 24-hour esophageal $\mathrm{pH}$ monitoring. The radiographic examinations used a standard approach to evaluate gastroesophageal reflux, described by McCauley [10]. This included a volume of barium approximating a normal feeding and intermittent fluoroscopy for 5 minutes with delayed films at 15-60 minutes. The gastroesophageal reflux was graded: 1 , to distal esophagus; 2 , to level of carina; 3 , to thoracic inlet; 4 , to pharynx; D, above or at carina seen on delayed film [10]. Reflux was said to be present radiographically if contrast appeared above the distal esophagus after once clearing completely. Significant or pathologic reflux was defined as at least 2 episodes of reflux to or above the carina after initial clearing of contrast from the esophagus. Two of the studies were done at an outside institution.

Esophageal $\mathrm{pH}$ monitoring was carried out using a Beckman pH meter (Beckman Instrument Inc., Novi, MI) and a strip chart recorder. A Beckman reference electrode \#40249 was secured on the forearm. A 1.22-mm nasogastric $\mathrm{pH}$ electrode (\# MI-505, Micro-electronics, Inc., Londonderry, NH) 
was passed through the nose and positioned in the esophagus at the level of the midatrium, at least $2.5 \mathrm{~cm}$ above the cardioesophageal junction. The $\mathrm{pH}$ probe was initially placed using the esophageal length calculation of Strobel et al. [11]. The position was then confirmed by chest radiography. The probe was repositioned as necessary. Patients were allowed a regular diet, but no between-meal snacks. Intermittent feedings with apple juice were used to confirm the functioning of the equipment. Monitoring for the full 24 hours was completed in all patients. The strip charts were analyzed for 4 parameters, and a fifth parameter was calculated [7]. These included the percentage of time that the $\mathrm{pH}$ was less than 4 (normal greater than 4.2 ), the number of reflux episodes (defined as a $\mathrm{pH}$ less than 4 ; the normal number is less than 50 ), the number of reflux episodes lasting 5 minutes or more (normal is less than or equal to 3), and the duration of the longest episode of reflux (normal is less than $9.2 \mathrm{~min}$ ). The gastroesophageal reflux (GER) index was calculated using the formula $X+4 Y=$ GER index, where $X$ is the number of episodes of a $\mathrm{pH}$ less than or equal to 4 and $Y$ is the number of episodes of a $\mathrm{pH}$ less than or equal to 4 for more than 5 minutes. Normal is 50 or less [7]. When 3 of the 5 parameters were positive, a diagnosis of significant or pathologic gastroesophageal reflux by $\mathrm{pH}$ monitoring criteria was made. In no case were 3 parameters positive and the GER index less than 50. All positive GER index cases had 3 or more other positive parameters, except for 1 case with only 2 , which was included as a positive result.

\section{Results}

All but 2 of the 34 patients had clinical symptoms strongly suggesting significant or pathologic gastroesophageal reflux including vomiting, failure to thrive, apnea, and pulmonary problems. The pulmonary problems included chronic cough, lobar atelectasis, and recurrent pneumonia.

A total of 16 children $(47 \%)$ had documented significant or pathologic gastroesophageal reflux. Eleven children had a positive diagnosis on $\mathrm{pH}$ monitoring: 9 were treated medically, and 2 had surgical intervention. Nine children with gastroesophageal reflux by radiographic criteria were all treated medically. In 4, both tests were positive. Only 2 children (those treated surgically) had follow-up contrast studies demonstrating no significant gastroesophageal reflux. None of the children had follow-up $\mathrm{pH}$ monitoring studies. None of the $5 \mathrm{pH}$ monitoring criteria correlated with either the overall radiographic impression or the highest level of reflux documented fluoroscopically. Three of the 4 measured $\mathrm{pH}$ monitoring criteria correlated well with each other $(p<0.05)$. Only the duration of the longest reflux correlated poorly with the other criteria $(p>0.05)$. The calculated GER index also correlated significantly with these 3 measured criteria and only failed to correlate significantly with the duration of the longest reflux.

In the 9 patients with significant gastroesophageal reflux on contrast studies, the calculated GER index ranged from 3 to 112 , with a mean of 58.9 .
The GER index in patients with no reflux seen at all radiographically ranged from 0 to 72 , with a mean of 38.7. The GER index in the patients with any type of reflux seen radiographically, significant or not, ranged from 2 to 112 , with a mean of 45.0 .

Six of the 16 children (38\%) with gastroesophageal reflux documented by either criterion are brain-damaged, and 1 child has associated problems including congenital heart disease. Four of the 6 brain-damaged children were diagnosed on upper gastrointestinal series, and 4 had a positive $\mathrm{pH}$ probe test (in 2, both tests were positive). Four of the children with positive contrast studies were under 2 years and 5 were over 2 years of age.

\section{Discussion}

Objective tests for significant or pathologic gastroesophageal reflux in the pediatric population have only shown fair correlation with the clinical symptoms $[5,10]$. The distinction between normal and abnormal gastroesophageal reflux can be difficult since there is a wide spectrum from the normal to the abnormal. Normal "burping" with regurgitation must be differentiated from pathologic or significant gastroesophageal reflux leading to morbidity and mortality $[1,5]$. It is important to detect those patients with significant or pathologic gastroesophageal reflux before they show advanced clinical complications.

In this study of patients with clinically suspected gastroesophageal reflux, a positive test was documented in only 16 patients. Of these, in only 4 patients did both $\mathrm{pH}$ probe and contrast studies document significant or pathologic gastroesophageal reflux. The patient population documented on contrast study did not differ from the general population of test-positive patients by age or associated clinical findings. We cannot suggest that the $\mathrm{pH}$ probe or upper gastrointestinal study is of more value in any particular group of patients presenting with clinically suspected disease.

Since gastroesophageal reflux occurs intermittently, 24-hour monitoring with $\mathrm{pH}$ probe has the advantage of a longer observation period to allow development of a physiological profile for the patient's esophagus. However, tracheobronchial aspiration is probably an intermittent, though devastating, event and may not be picked up as a positive score, although a single significant episode can be documented on a contrast study. The upper gastrointestinal study, in addition, documents the level of reflux as well as giving information at the time of the study about the swallowing mechanism. 
Esophageal motility, hiatal hernia, and esophageal stricture can also be documented. Contrast studies further help to eliminate other conditions including pyloric stenosis, antral web, annular pancreas, and gastric outlet obstruction from any cause. Gastric emptying can also be monitored.

The $\mathrm{pH}$ monitoring criteria did not correlate with any of the radiographic criteria. Some studies have suggested that $\mathrm{pH}$ monitoring is more sensitive than contrast studies [9] and others have suggested that contrast studies done in a standard method are accurate [1].

We believe that the upper gastrointestinal study and 24-hour $\mathrm{pH}$ monitoring probably measure different aspects of significant or pathologic gastroesophageal reflux. In any 1 patient with strongly suggestive clinical symptoms, any objective test that can document the presence of reflux is important to document the problem and evaluate the need for and effectiveness of therapy. These 2 methods are complementary and confirmatory, and must be correlated with the clinical symptoms to be of any value. Clearly the diagnosis of significant gastroesophageal reflux remains inexact and there still is an important role for the upper gastrointestinal study in the child with a history suggestive of gastroesophageal reflux.

\section{References}

1. Herbst JJ: Gastroesophageal reflux. J Pediatr 98:859-870, 1981
2. Schatzlein MH, Ballantine TVN, Thirunavukkarasu S, Fitzgerald JF, Grosfeld JL: Gastroesophageal reflux in infants and children. Arch Surg 114:505-510, 1979

3. Wesley IR, Coran AG, Sarahan TM, Klein MD, White SJ: The need for evaluation of gastroesophageal reflux in brain-damaged children referred for feeding gastrostomy. $J$ Pediatr Surg 16:866-871, 1981

4. Blane CE, Wesley JR, DiPietro MA, White SJ, Coran AG: Gastrointestinal complications of gastroschisis. $A J R$ 144: $589-591,1985$

5. Hill JL, Pelligrini CA, Burrington JD, Reyes HM, DeMeester TR: Technique and experience with 24-hour esophageal $\mathrm{pH}$ monitoring in children.J Pediatr Surg 12:877-887, 1977

6. Arasu TS, Wyllie R, Fitzgerald JF, Franken EA, Siddiqui AR, Lehman GA, Eigen H, Grosfeld JL: Gastroesophageal reflux in infants and children - comparative accuracy of diagnostic methods. J Pediatr 5:798-803, 1980

7. Euler AR, Byrne WJ: Twenty-four-hour esophageal intraluminal pH probe testing: a comparative analysis. Gastroenterology 80:957-961, 1981

8. Jolley SG, Johnson DG, Herbst JJ, Pena A, Garnier R: An assessment of gastroesophageal reflux in children by extended $\mathrm{pH}$ monitoring of the distal esophagus. Surgery $84: 16-24,1978$

9. Sondheimer JM: Continuous monitoring of distal esophageal $\mathrm{pH}$ : a diagnostic test for gastroesophageal reflux in infants. $J$ Pediatr 96:804-807, 1980

10. McCauley RGK, Darling DB, Leonidas JC, Schwartz AM: Gastroesophageal reflux in infants and children: a useful classification and reliable physiologic technique for its demonstration. AJR 130:47-50, 1978

11. Strobel CT, Byrne WJ, Ament ME, Euler AR: Correlation of esophageal lengths in children with height: application to the Tuttle test without prior esophageal manometry. $J$ Pediatr 94:81-84, 1979

Received: August 20, 1985; accepted: October 14, 1985 